\title{
Developmental characteristics of sporogenous hyphae: a new observation between Brassica juncea var. tumida and Albugo candida
}

\author{
Zilan Xiao $\cdot$ Ning Gong $\cdot$ Xiaojun Zhou \\ Liyan Zhu $\cdot$ Xiaochan He $\cdot$ Jingwu Zheng $\cdot$ \\ Jingze Zhang
}

Accepted: 1 October 2021 / Published online: 9 October 2021

(C) Koninklijke Nederlandse Planteziektenkundige Vereniging 2021

\begin{abstract}
Brassica juncea var. tumida (tumorous stem mustard) is widely cultivated as a feature vegetable in Ningbo, Zhejiang Province, and is used as a raw material for pickles in China. White blister rust, caused by Albugo candida, has severe negative effects on tumorous stem mustard, resulting in significant economic losses. In this study, hypha colonization and extension, haustorial formation, and the development process of sporogenous hyphae and sporangia in A. candida-infected tissues were studied using light and transmission electron microscopy. Additionally, the complex and unique sporogenous hypha developmental process was revealed. During A. candida infection, cytological and ultrastructural characteristics were similar to those of cruciferous plants. During sporogenous hyphae development, an initially cylindrical sporogenous hypha with a thin inner wall at the apex developed from a cell with a thick inner wall. At the apical end of the sporogenous hypha, an
\end{abstract}

Z. Xiao $\cdot$ J. Zheng $\cdot$ J. Zhang $(\bowtie)$

Ministry of Agriculture, Key Lab of Molecular Biology of Crop Pathogens and Insects, Institute of Biotechnology, Zhejiang University, Hangzhou 310058, China

e-mail: jzzhang@zju.edu.cn

N. Gong

Shanghai Municipal Landscape Management and Instructional Station, Shanghai 200020, China

X. Zhou $\cdot$ L. Zhu $\cdot$ X. He

Jinhua Academy of Agricultural Sciences, Jinhua 321017, China electron-dense complex gathered, causing the disintegration of the inner and outer walls and the formation of new inner and outer walls. With the formation of a clavate sporogenous hypha, a deep constriction of the cell wall occurred at its subapex, in which a septum was produced and a primary sporangium was separated from the sporogenous hypha. Both layers of the sporogenous hypha wall took part in the formation of the sporangial wall but were not related the formation of the sporangial outer wall in a septum, providing direct evidence of the holoblastic formation of sporangia. Furthermore, ultrastructural observation demonstrated that the development of the primary sporangial walls within a septum occurred later than that of their lateral walls, including the degradation of constricted outer walls around the septum, formation of the inner wall and subsequent outer walls of a sporangium in the upper septum layers, confirming the earlier observation. Therefore, this study provided the model of sporogenous hyphae development and sporangial formation in chain.

Keywords Albugo Brassica juncea var. tumida . Fungus-host interactions · Holoblastic, ultrastructure

\section{Introduction}

Tumorous stem mustard (Brassica juncea var. tumida M. Tsen \& S.H. Lee), a variety of B. juncea belonging to the Cruciferae family (Sun et al., 2013), is widely 
cultivated as a feature vegetable in Ningbo, Zhejiang province, and is used as a raw material for pickles in China. White blister rust is a destructive disease, usually occurring in different varieties of tumorous stem mustard, causing significant economic losses (Choi et al., 2008; Sokhi \& Khangura, 1992; Voglmayr \& Riethmuller, 2006). Thus, it poses a potential risk to the tuber mustard growing industry in Ningbo.

White blister rust of tumorous stem mustard is caused by Albugo candida (Pers. ex J.F. Gmel.) Roussel (Arora et al., 2019; Bhayana et al., 2019). Molecular phylogenetic relationships in the A. candida complex have revealed several new species (Voglmayr \& Riethmuller, 2006; Choi et al., 2006, 2007, 2008; Petkowski et al., 2010) and host specificity and genetic diversity within the Albugo candida (Choi et al., 2006; Ploch et al., 2010) also are investigated widely. Morphologically, cell wall thickenings of maturation all sporangia are typical for the respective lineages of the Albuginaceae (Heller \& Thines, 2009). Almost no changes of cell wall thickenings occurred in A. candida sporangia, a more or less evenly distributed cell wall thickening in A. ipomoeae-panduratae, crescent moon like thickenings in the secondary sporangia of Wilsoniana, and typical lenticular equatorial wallthickenings in the primary and secondary sporangia of Pustula (Heller \& Thines, 2009). Albugo candida is an obligate pathogen responsible for white rust in brassicaceous hosts over widely differing geographical areas worldwide (Choi et al., 2007). The disease symptoms in tumorous stem mustard are similar to those in other crops (Sokhi \& Khangura, 1992); i.e., it forms white to cream-colored zoosporangial pustules (sori) on the leaves, stems, and inflorescences (Verma \& Petrie, 1980). Hence, the disease caused by A. candida is referred to as white blister rust (Holub et al., 1995). The A. candida lifecycle is also similar among infected plants: the sori contain masses of sporangiospores that produce basipetal chains of sporangia, which are formed between the epidermal and mesophyll tissues of their hosts. These sporangia are released by the rupture of host epidermis and germinate either directly by producing germ tubes, or indirectly by producing zoospores. Zoospores can enter into stomatal openings, encyst, and produce a germ tube in the sub-stomatal chamber, which then penetrates the host cell producing intercellular hyphae in a pathogen-host interaction (Borhan et al., 2001; Holub et al., 1995). Finally, sori develop beneath the host epidermis cells. However, A. candida is characterized by its high degree of host specificity (Petkowski et al., 2010). Morphologically identical isolates of $A$. candida may be highly specialized on a given host genus or species (Petkowski et al., 2010; Pound \& Williams, 1963; Verma et al., 1999). The relationship of host-pathogen interactions has been investigated to help define the disease development in susceptible host plants.

Cytological and ultrastructural observations of $A$. candida-host interactions have been widely investigated using light and electron microscopy on cruciferous plants, such as radish (Berlin \& Bowen, 1964), Cheiranthus cheiri L. cv. Blood red (Davison, 1968), Brassica oleracea (Coffey, 1975, 1983), Cardamine hirsuta (Woods \& Gay, 1983), Brassica campestris (Tewari et al., 1980), rapeseed (Tewari \& Skoropad, 1977), Raphanus sativus (Khan, 1976, 1977), Arabidopsis thaliana (Soylu, 2004), and Arabis alpina (Baka, 2008). Regarding the interactions between Arabidopsis accessions and Albugo candida races isolated from different hosts, the ultrastructural characteristics of pathogen-host interactions in susceptible and resistant hosts have been clearly elucidated (Holub et al., 1995; Soylu, 2004; Soylu et al., 2003). In the infection of Arabis alpina by Albugo candida, unique characteristics of the extrahaustorial membrane that produces several unique tubular elements have been observed in the interaction at the interface between a haustorium and the host cell membrane (Baka, 2008). However, although A. candida isolates on Brassica juncea exhibit a high level of host specificity (Kaur et al., 2011a), and proteome analysis of the $A$. candida $-B$. juncea pathosystem revealed that expression timing of defense-related genes is a crucial determinant of pathogenesis (Kaur et al., 2011b), ultrastructural studies of pathogen-host interactions have not been conducted. Several authors have, however, examined the development of asexual and sexual reproductive structures of $A$. candida, such as sporangium formation, changes in maturing sporangia, and oospore development by electron microscopy (Khan, 1976, 1977; Tewari \& Skoropad, 1977). Furthermore, Heller and Thines (2009) revealed the process of pustule development and opening in white blister rusts by cytological and ultrastructural observations, and they provided evidence for the importance of enzymatic digestion of epidermal 
walls during subepidermal sporulation and pustule opening. They proposed to use the term "vegetative hyphae" to replace "sporangiophore", owing to the absence of septa between the vegetative hyphae and the sporogenous hyphae. However, the detailed developmental process of sporogenous hyphae and sporangial formation has not been elucidated clearly.

Therefore, in this study, the cytological and ultrastructural characters of interactions between $A$. candida and $B$. juncea var. tumida were systematically described, focusing on the developmental processes of sporogenous hyphae and continuous sporangia formation. This study provides new insights for understanding the unique and complex developmental pattern of A. candida sporogenous hyphae.

\section{Materials and methods}

Samples were collected from naturally infected leaves of B. juncea var. tumida at different development stages in a field in Simen Town (Yuyao City, Zhejiang Province, China) on March 21, 2018. Tissue samples $(1 \times 2 \mathrm{~mm})$ with $A$. candida mycelia and sori were fixed in glutaraldehyde $(2.5 \%)$ in a $0.1 \mathrm{~mol} / \mathrm{L}$ sodium phosphate buffer $(\mathrm{pH} 7.0)$ under vacuum-infiltration for $5 \mathrm{~min}$ and then stored at $4{ }^{\circ} \mathrm{C}$ overnight. Samples were then washed with the same buffer after fixation and post-fixed in osmium tetroxide $(1 \%, \mathrm{w} / \mathrm{v})$ for $2 \mathrm{~h}$ at $20^{\circ} \mathrm{C}$. After dehydrating in a graded ethanol series, tissues were embedded in Spurr's epoxy resin. Infection sites and sori were identified using a Leica DM500 microscope (Leica Microsystems GmbH, Germany) at the precise stages of development, and ultrathin sections were cut with a Reichart-Jung ultracut E ultramicrotome with a diamond knife. Some of the sections were stained with trypan blue and images were acquired using a Zeiss Axiophot 2 microscope with an Axiocam CCD camera (Carl Zeiss, Göttingen, Germany) and AxioVision digital imaging software (AxioVision Software Release 3.1. ver. 3-2002; Carl Zeiss Vision Imaging Systems). Other ultrathin sections collected on Formvar-coated slot copper grids were stained with uranyl acetate and lead citrate and examined using a transmission electron microscope at $80 \mathrm{kV}$ and images were recorded with a Gatan 832 CCD camera (Hitachi H-7650, Tokyo, Japan).

\section{Results}

Cytological characters of hyphae and sporangia development

Light microscope examination of leaves revealed that the intercellular hyphae were smooth, regularly or irregularly swollen, and branched (Fig. 1A). The hyphae colonized and ramified between the intercellular spaces in mesophyll tissues (Fig. 1A) or between the parenchymal cells. Occasionally, they colonized and ramified between host cells in the palisade tissues. The globular haustoria could be seen in closecontact points between the fungal hypha and the host cell wall. Furthermore, chloroplasts were present near the inner walls of the host cells.

After reaching a certain maturity, intercellular hyphae produced a sorus with several sporangia, mainly between the mesophyll cells and the host epidermis (Fig. 1B). As a result of sorus development, numerous zoosporangia formed, the sorus size increased, and epidermal cells collapsed markedly, slightly raising the host epidermis (Fig. 1C). Sporangia were produced in chains at the tips of the short, unbranched, and club-shaped sporogenous hyphae (Fig. 1D). The continued growth and production of sporangia led to the rupture of the enveloping epidermis and the release of the sporangia (Fig. 1F). However, as described by Heller and Thines (2009) and based on characteristics of the residuals of the epidermis, the ruptured epidermal layer could be attributed to enzymatic digestion instead of mechanical pressure owing to lack of signs of tearing of the epidermis (Fig. 1F, see arrowheads). The sporogenous hyphae were arranged in palisade-like layers, forming sori between the epidermis and the host palisade tissues.

\section{Interactions between hyphae of $\boldsymbol{A}$. candida and the host}

Transmission electron microscopy (TEM) was used to examine the ultrastructure of the intercellular hyphae 
Fig. 1 Light micrograph of Albugo candida hyphae and development of zoosporangia in sori beneath the host (Brassica juncea var. tumida) peridermis. A. Hyphae between mesophyll cells. A haustorium (arrow) in a mesophyll cell produced from a hypha (arrowhead) penetrating the host cell wall; B. Sorus with the production of many sporangia beneath the host peridermis (arrowhead); C. Larger sorus with numerous sporangia beneath the host epidermis (arrowhead), which collapses and becomes slightly elevated; D. Zoosporangia (S) in chains and clubshaped sporogenous hyphae (arrowhead); E. Sorus filled with a few zoosporangia below the ruptured epidermis. Note that the residuals of the epidermis (arrowhead) are degraded. Bars: $\mathbf{A}-\mathbf{D}=10 \mu \mathrm{m} ; \mathbf{E}=50 \mu \mathrm{m}$
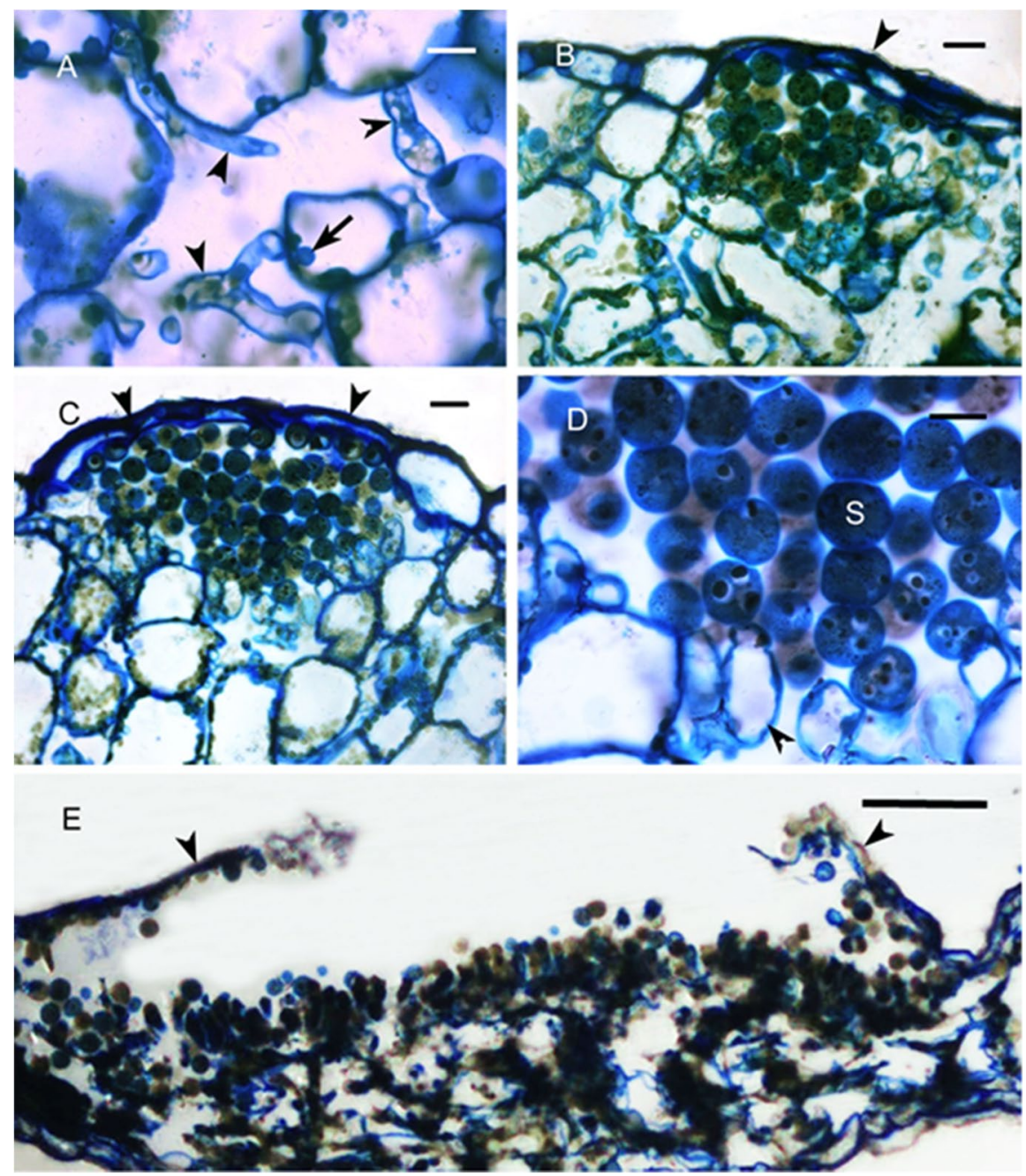

and haustoria, as well as the host cell response in infected tissues. Intercellular hyphae were observed in the intercellular spaces of the host leaf tissue (Fig. 2A). Two types of hyphae, with thin $(0.9-1.0 \mu \mathrm{m})$ or thick cell walls $(1.4-2.0 \mu \mathrm{m})$, were observed in the intercellular spaces of mesophyll cells. Hyphae with thin cell walls were involved in fungal growth in these spaces, whereas those with thick cell walls interacted with the host cells (Fig. 2B and C). The first sign of pathogen penetration in a host cell was the formation of a penetration peg originating from the thick-walled intercellular hyphae (Fig. 2B), which caused the host cell wall to seriously invaginate and subsequently become penetrated, forming a spherical haustorium (Fig. 2A) and D). The haustorial bodies $(n=30)$ were 3.8-4.0 $\mu \mathrm{m}$ in diameter and connected to the intercellular hyphae by a narrow, slender, cylindrical neck
(1.3-1.5 $\times 0.3-0.5 \mu \mathrm{m})$. In infected cells, haustoria were surrounded by an electron-dense interfacial matrix that separated the haustorium wall from an invaginated host plasma membrane, i.e., the extrahaustorial membrane. With aging, the cytoplasm of the haustoria gradually became disorganized, several large vacuoles appeared, and the mitochondria were degraded (Fig. 2E). A necrotic haustorium was often misshaped, with an irregular appearance, and dense content (Fig. 2F).

\section{Observations of sporogenous hyphae development and sporangial formation}

The initial sporogenous hyphae developed from the thick-walled hyphae between the epidermis and mesophyll cells (Fig. 3A). The cell of a thick-walled 


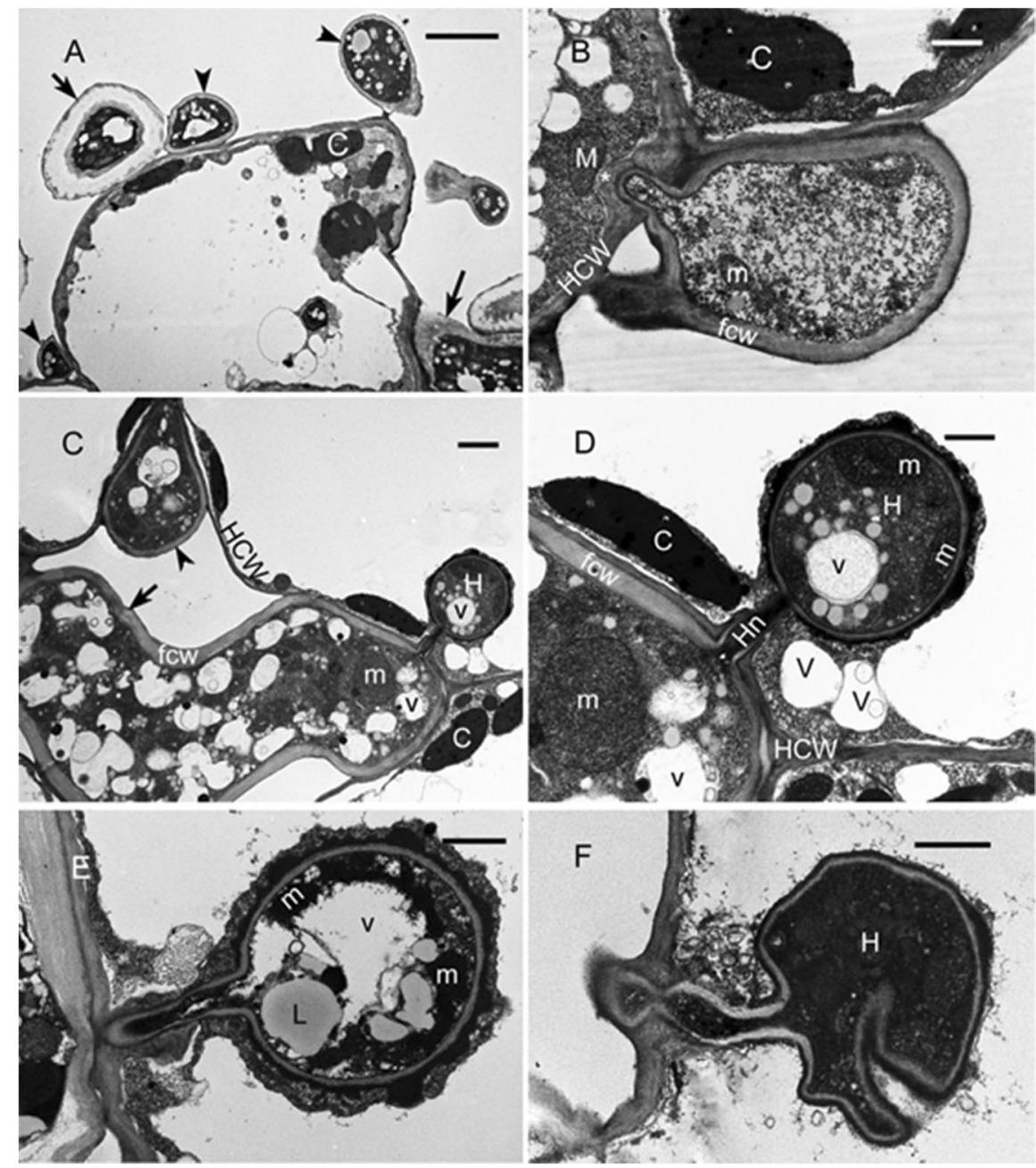

Fig. 2 Ultrastructural features of the interactions between Albugo candida hyphae and the host Brassica juncea var. tumida. A. Transverse section of hyphae in the intercellular spaces of mesophyll tissue; hyphae with thin (arrowheads) or thick (arrows) cell walls are evident as well as chloroplasts (indicated by the letter C). B. An intercellular hypha (IH) initially invades the host cell wall $(\mathrm{HCW})$ via a penetration peg (arrow) causing the host cell wall (HCW) to invaginate (*). Note the thick wall (fcw) of the intercellular hypha (IH), fungal mitochondria (m), and host cell organelles such as mitochondria (M), C, and HCW; C. Transverse section of intracellular hyphae among host cells; hyphae with thin (arrowhead) or

hypha developed upward to form cylindrical or hooked structures (initial sporogenous hyphae) with a cell wall composed of two parts, i.e., a thin electron-dense outer layer and a thick electron-opaque inner layer. The inner layer was plastic and abruptly became narrow near the mid-section (Fig. 3A). thick (arrow) cell walls are evident. A haustorium is connected to large intercellular hyphae via a penetration point; D. Magnified view of part of the fungal invasion shown in Fig. 2C. A haustorium with a slender haustorial neck (hn) is surrounded by the electron-dense extrahaustorial matrix; E. Aging haustorium; F, Necrotic haustorium. Note the collapse of a mesophyll cell. $\mathrm{H}$, haustorium; $\mathrm{Hn}$, haustorium neck; IH, intercellular hyphae; fcw, fungal cell wall; HCW, host cell wall; m, fungal mitochondrion; M, host mitochondrion; v, vacuole in fungal cell; V, vacuole in host cell; $\mathrm{L}$, lipid body. Bars: $\mathbf{A}=5 \mu \mathrm{m} ; \mathbf{B}$, D, $\mathbf{E}, \mathbf{F}=1 \mu \mathrm{m} ; \mathbf{C}=2 \mu \mathrm{m}$

Subsequently, a sporogenous hypha became more or less regularly cylindrical (Fig. 3B). The electrondense outer and inner walls gradually became thicker and thinner, respectively, from lower to higher positions, and seemed to disappear at the apex (Fig. 3B). Meanwhile, electron-dense material and organelles 

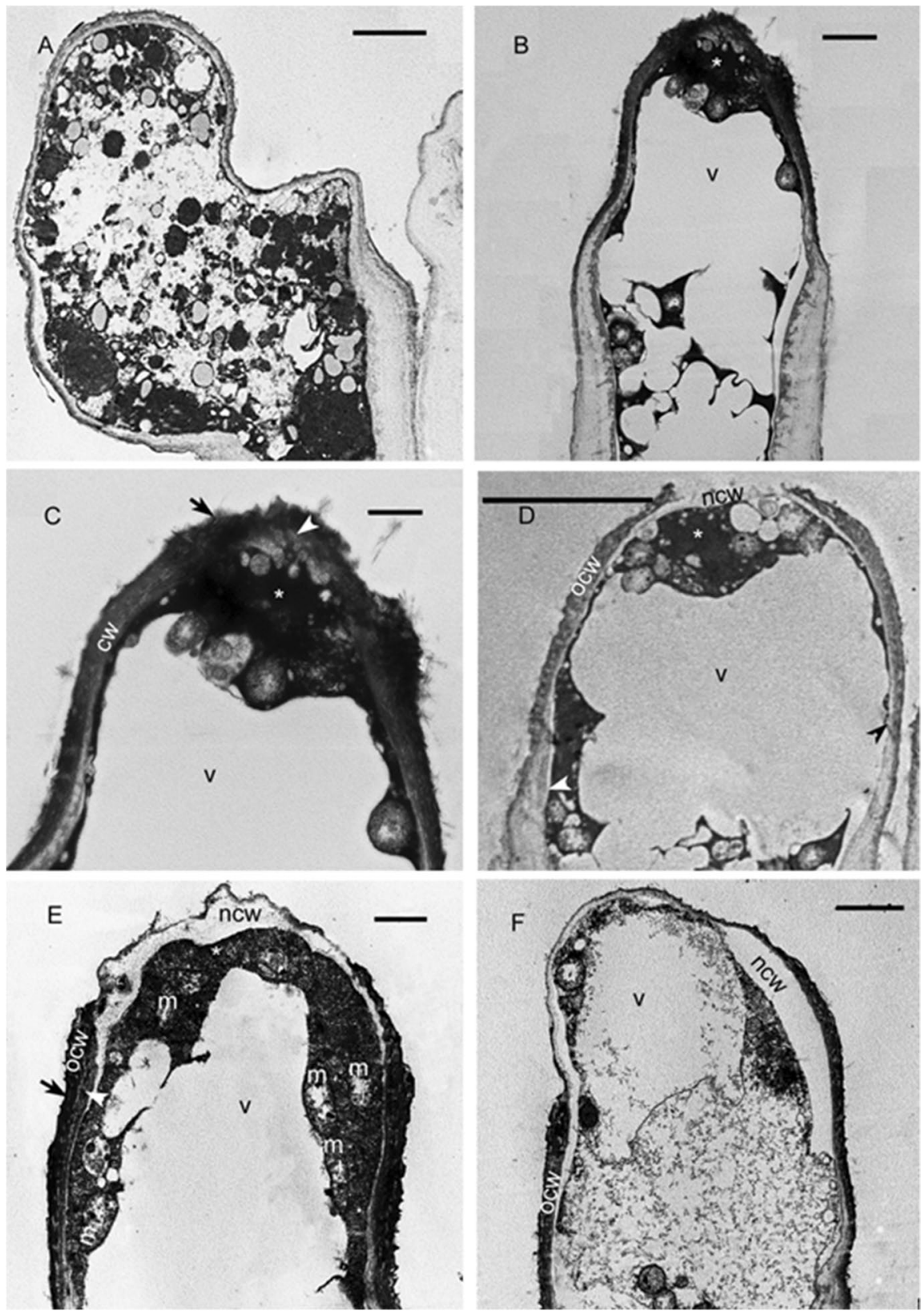

accumulated beneath the apex, forming a large complex surrounding a large vacuole. During this period, the apical cell wall was degraded forming debris containing granular and villiform filament materials (Fig. 3C). As the debris disappeared, the new cell wall (NCW) began to form. The electron-translucent NCW layer developed as the electron-opaque inner wall gradually became thicker from bottom to top (Fig. 3D), and combined with the electron-dense outer wall due to the disappearance of the inner wall. Meanwhile, the outer wall at the apex was completely degraded. With development, the large complex beneath the apex contained several mitochondria around a large vacuole extending down along the plasma membrane (Fig. 3E). The area of the degraded outer wall became completely enlarged, and the thickness increased in the newly-formed wall, although its surface was irregularly wavy (Fig. 3E). 
4Fig. 3 Transmission electron micrographs of Albugo candida sporogenous hypha development. A. An initial sporogenous hypha with a thick-walled lower portion and a thin-walled upper portion; B. Apical cell wall degradation. An electrondense complex $(*)$ containing an organelle on a large vacuole (v) attached above the apical cell wall causing its degradation; C. Magnified view of the apical cell wall shown in Fig. 3B. The damaged apical cell wall contains granular (arrowhead) and villiform filament (arrow) materials above an electron-dense complex (*) around a large vacuole (v); D. Degradation of an apical cell wall and new cell wall formation. The partial cell wall at the apex is completely degraded, as well as the new cell wall (arrowheads) produced between the old cell wall (ocw) and the plasma membrane around the electron-dense complex $(*)$, which is discontinuous with the old cell wall; E. Uneven development of a new cell wall. The new cell wall (ncw) around the plasma membrane encloses the electron-dense complex $(*)$. The new cell wall (ncw) extending downward is electron-opaque, with irregular thickness; the ncw developed between the electron-dense old cell wall (ocw) and the plasma membrane. Note that the old cell wall with the electron-dense outer wall (arrow) and light electron-dense inner wall (arrowhead) is visible and the electron-dense complex contains numerous mitochondria (m); F. Biased development of apical growth. Degradation of the old cell wall (ocw) is asymmetric on two sides, and new cell wall (ncw) development is uneven in thickness. Note that the electron-dense complex disappears and the large vacuole is disorganized. Bars: A, $\mathbf{C}=1 \mu \mathrm{m} ; \mathbf{B}, \mathbf{D}, \mathbf{E}, \mathbf{F}=2 \mu \mathrm{m}$

The thin electron-dense material covered the irregular NCW; this was clearly the newly-formed outer wall, while the NCW was the inner layer (Fig. 3E). Occasionally, fissures in the ruptured old wall could be seen. Thereafter, the surface of the newly-formed cell wall gradually became regular (Fig. 3F). However, the development of the uneven newly-formed inner wall and the asymmetric degradation of the old outer cell wall sometimes led to a bias in the apical growth of a developing sporogenous hypha (Fig. 3F). At this stage, the electron-dense complex gradually disappeared and the large vacuole began to disorganize. Soon afterwards, with development of the new outer and inner walls at the apex, regular conical apexes was formed on a clavate sporogenous hypha (Fig. 4A). The sporogenous hyphae were 26.5-28 $\times 11.5-13.0 \mu \mathrm{m}$ (length $\times$ width). During this stage, the newly-formed cell wall became uniform in thickness. The inner and outer walls of the lower part of sporogenous hyphae fused with the old inner and outer walls, respectively. However, these walls could still be distinguished by their narrowness compared to the wide, old outer wall with non-degraded residual and relatively electron-dense inner wall (Fig. 4B and
D). Additionally, the apical part of a sporogenous hypha had electron-dense materials and several mitochondria in the cytoplasm (Fig. 4C), and numerous large vacuoles were distributed below this apical part (Fig. 4A). The residuals of the old degraded cell wall appeared as villiform materials on the apex surface (Fig. 4C). Shortly thereafter, a strong constriction occurred at the sub-apex side of the sporogenous hypha, which initiated the development of the sporangial initial cell (Fig. 4E), also called as primary sporangium by Heller and Thines (2009). The constricted cell wall was continuous from both layers of the sporogenous hypha wall to those of the initial sporangial wall (Fig. 4F).

As a result of primary sporangial development, a young septum was produced from the site of the constricted cell wall (Fig. 5A), separating the initial sporangium from the sporogenous hypha. The septum clearly developed from the inner wall, while partial degradation began to occur at the intersection angle between the lateral wall and the margins of a septum (Fig. 5C). Simultaneous to the formation of the primary septum and the apical extension of the sporogenous hypha, cell wall constriction appeared again below the primary sporangium (Fig. 5B, left) and marked the secondary sporangial initial cell, as described by Heller and Thines (2009). As a result of primary sporangial development, their inner walls formed gradually and the outer wall was degraded on the septum between the two sporangia (Fig. 5E). When a septum disintegrated to form a connective structure, partially developing outer walls of the primary sporangia began forming beneath the inner wall in the connective tissue (Fig. 5F). Evidently, the inner and outer walls of sporogenous hyphae did not participate in the formation of the inner and outer walls of the sporangia in a septum. Figure 5B clearly shows the formation process of the primary and secondary sporangia through the different development stages of two sporogenous hyphae.

\section{Observations of sporangial development}

The sporangia of $A$. candida were produced in basipetal succession on a sporogenous hypha. Figure 6A shows the different stages of secondary sporangial development in a sporangial chain with very few changes in thickenings of the sporangial cell 

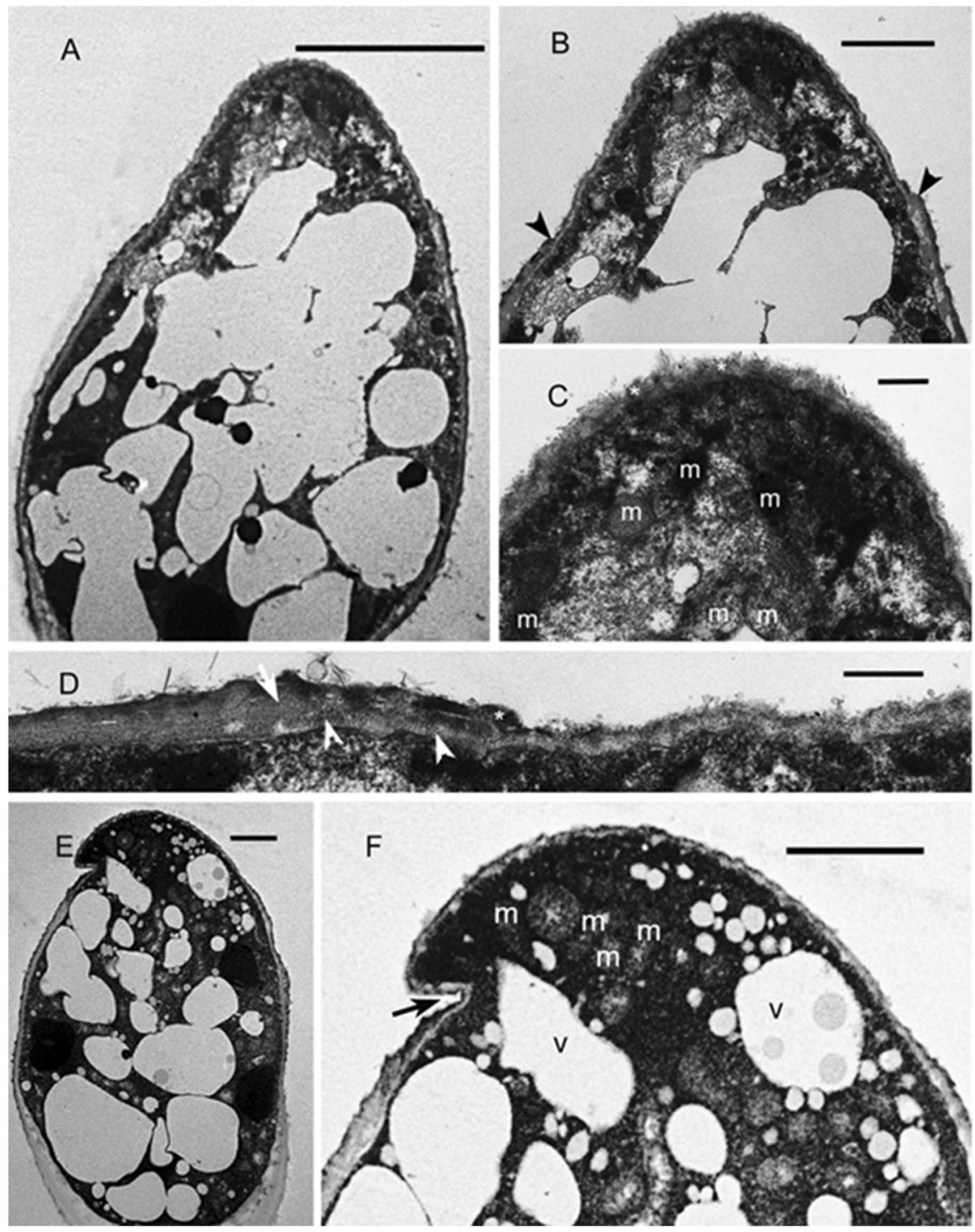

Fig. 4 Transmission electron micrographs of Albugo candida sporogenous hypha development from typical sporogenous hypha formation to initial sporangium production. A. Typical sporogenous hypha; B. Magnified view of the apex in Fig. 4A. The new cell wall is uniform in thickness but can be distinguished from the site of incompletely undegraded old cell walls (arrowheads); C. Magnified view of the apex in Fig. 4B. The cytoplasm contains electron-dense materials and numerous mitochondria $(\mathrm{m})$ at the apex. Note the villiform materials (*) on the cell wall surface; D. Magnified view of the side cell wall in Fig. 4A. The new cell wall (arrowheads) fuses with the undegraded old cell wall (arrow), although the residual (*) of the degraded old cell wall can still be seen; E. Deep constriction of the cell wall at the proximal subapex of a sporogenous hypha side. The upper part at the constricted site is the beginning of sporangium development; F. Magnified view of the apex of the sporogenous hypha shown in Fig. 4E. Both layers of the sporogenous hypha wall are continuous with the two layers of the initial sporangium wall, and the cytoplasm contains electron-dense materials and numerous mitochondria $(\mathrm{m})$ at the apex. v: vacuole. Bars: $\mathbf{A}, \mathbf{B}, \mathbf{F}=2 \mu \mathrm{m} ; \mathbf{C}, \mathbf{D}, \mathbf{E}=0.5 \mu \mathrm{m}$

and numerous electron-transparent vacuoles (Fig. 6B). However, in premature sporangia, this large vacuole containing electron-dense material disappeared, numerous mitochondria appeared, 


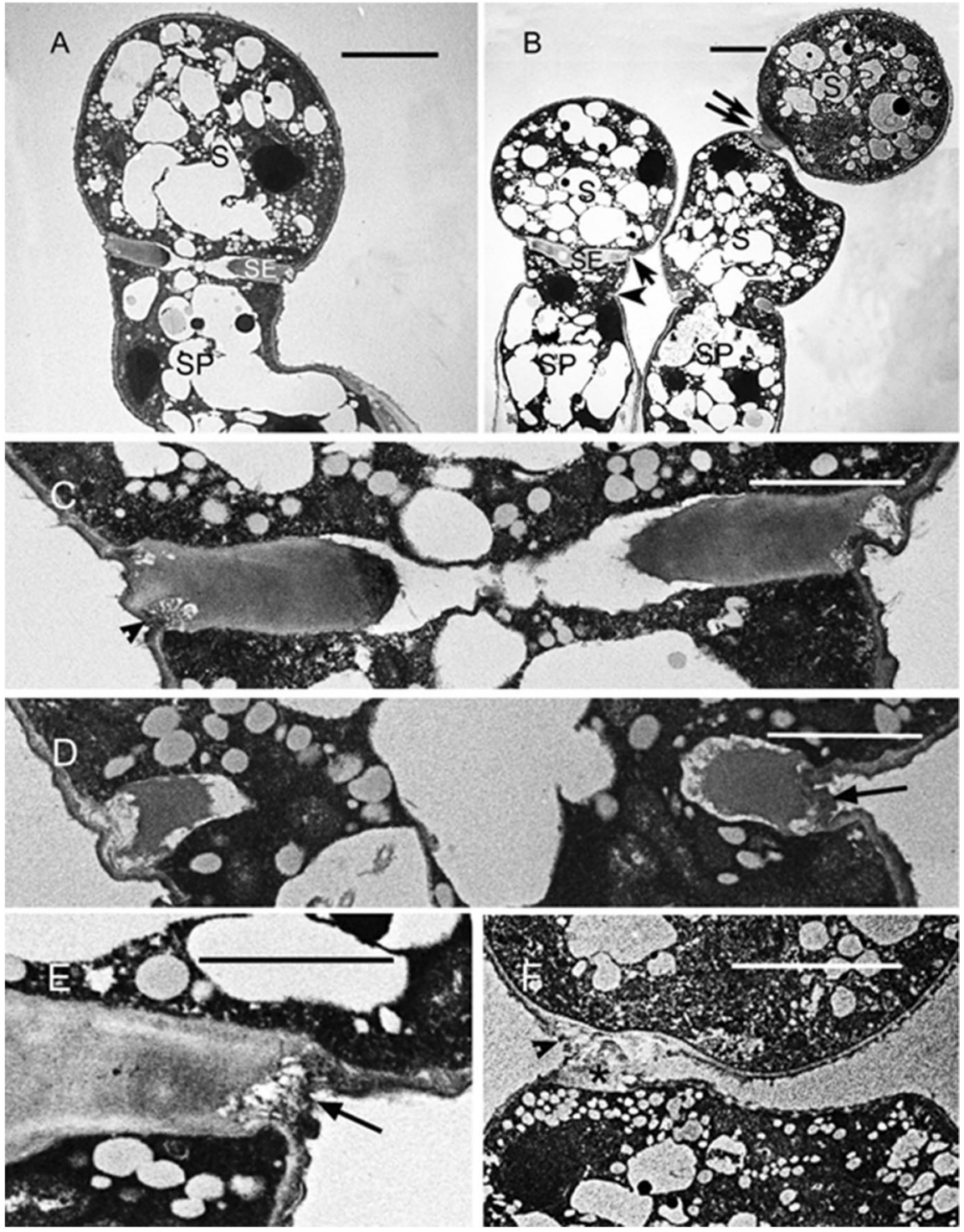

Fig. 5 Transmission electron micrographs of Albugo candida sporangium development. A. Developing sporangium (S) produced on a sporogenous hypha (SP). Developing septum (SE) separate the sporangium from the sporogenous hypha; B. Sporangia (S) at different developmental stages on two sporogenous hyphae (SP). A secondary initial sporangium developed between the apex of a sporogenous hypha (left, arrowhead) and the first sporangium (arrow) and is delimited by deep constrictions (arrowhead) or a developing septum (arrow). On the right sporogenous hypha, a septum between the first and $d$

and the primary sporangium wall increased slightly in thickness (Fig. 6C). During this period, a few mitochondria had deep median constrictions. Mature sporangium was multinucleate, had several disintegrated to form a connective structure (double arrows). C-D. Septa at different developmental stages; C. Magnified view of developing septum in panel A; note that a septum developed from the inner wall and that the partial outer wall is degraded (arrowhead). D. Magnified view of the outer wall being degraded (arrowhead) in panel B; E. Cell wall degradation at the constricted site and formation of sporangial walls; $\mathbf{F}$. Connection between two sporangia. The partial cell wall of the sporangia did not form (*) and the residual of the degraded cell wall can be seen (arrowhead). Bars: $\mathbf{A}-\mathbf{E}=2 \mu \mathrm{m} ; \mathbf{F}=5 \mu \mathrm{m}$

mitochondria, lipid bodies, vacuoles, and welldeveloped Golgi apparatuses, with few cisternae per apparatus (Fig. 6D and E). 
Fig. 6 Transmission electron micrographs illustrating Albugo candida sporangial development. A. Sporangial sizes increase on a sporangial chain from bottom to top; B. Low magnification view of the zoosporangium shown in Fig. 3A; two large vacuoles containing electron-dense material (*) surrounded by electron-transparent areas; C. A premature sporangium. Numerous mitochondria $(\mathrm{M})$ are visible and a few have deep median constrictions (*); D. A mature sporangium. Elements of the Golgi apparatus (G) are evident near the nuclear surface (N). Several mitochondria and lipid bodies (LB) are visible; E. Magnified view of a nucleus (N) shown in Fig. 6D. The Golgi apparatus (G) has few cisternae and the nuclear envelope is visible (NE). LB, lipid bodies; electrondense vacuoles (arrows), electron-transparent vacuole (arrowheads); HP, host epidermis. Bars: $\mathbf{A}=\mathbf{5} \mu \mathrm{m}$; $\mathbf{B}-\mathbf{D}=2 \mu \mathrm{m} ; \mathbf{E}=0.5 \mu \mathrm{m}$
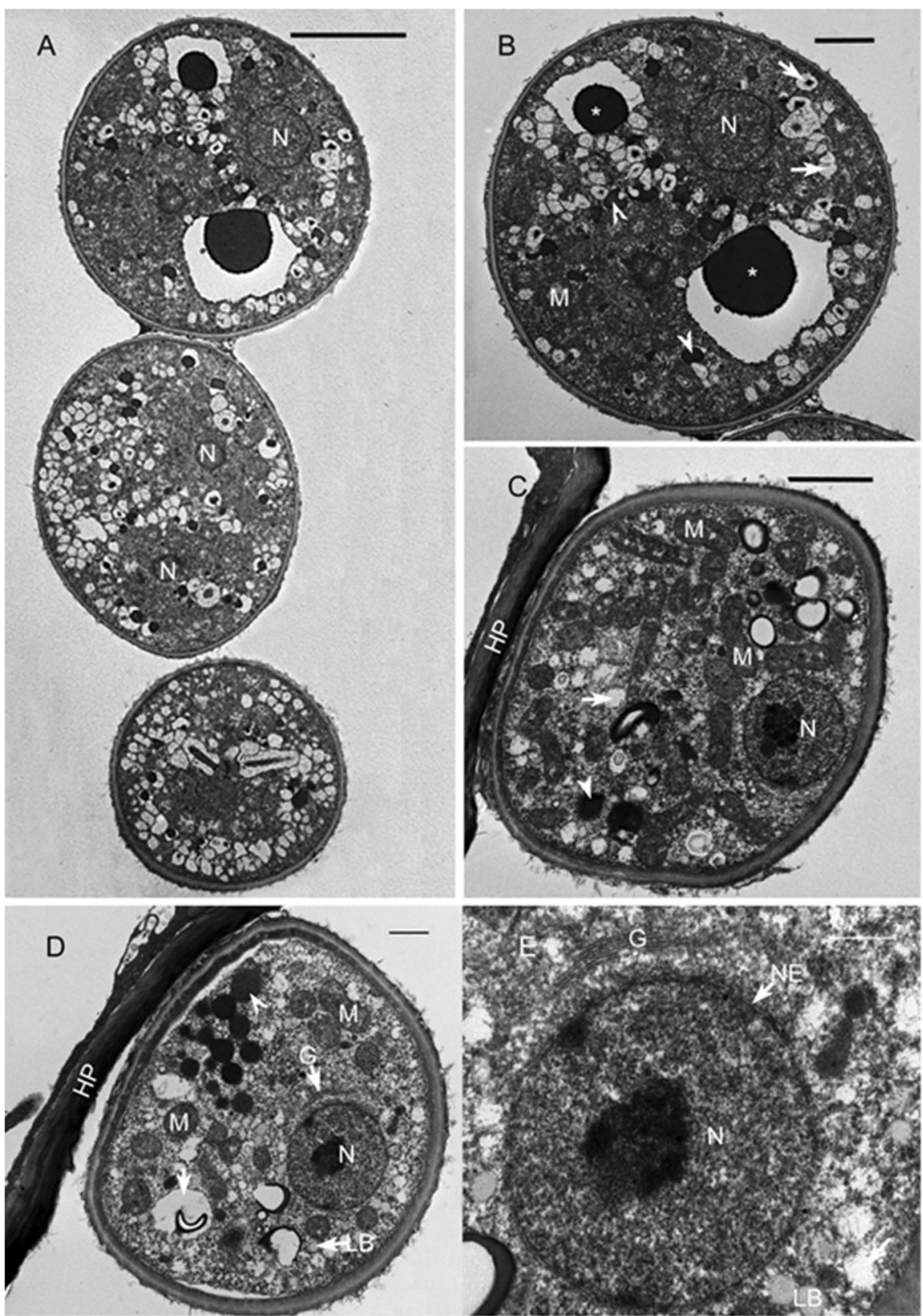

\section{Discussion}

Albugo candida is a biotrophic oomycete that parasitizes various species of Brassicaceae and causes white blister rust. The developmental process of $A$. candida in infected tissues has been widely investigated using light microscopy and TEM. In this study, the cytological and ultrastructural characteristics of A. candida infection in leaf tissues of B. juncea var. tumida were observed, including smooth and irregular hyphae colonization, extension between cells or intercellular spaces, and haustorial formation. Ultrastructural observations showed a thick-walled hypha in close contact with the host cell wall, producing a thin-walled penetration peg which entered the cell wall, forming a swollen and globular haustorium, surrounded by a host plasma membrane. These characteristics are in agreement with those identified in 
previous studies investigating white rust on cruciferous plants (Holub et al., 1995; Soylu, 2004; Soylu et al., 2003). When hyphae developed to a certain stage, sporangia were typically produced from the apex of the intercellular hyphae between the epidermis and mesophyll cells, as described by Soylu et al. (2003) and Khan (1977). However, previous studies did not assess the developmental processes of sporogenous hyphae. Although the blastic mode of sporangiogenesis in Albugo has not been questioned (Constantinescu \& Thines, 2006), the percurrent character of this process claimed by Hughes (1971) and Thakur (1977), was contested by Khan (1977). More recently, the mode of sporangiogenesis in Albuginaceae was described by Heller and Thines (2009), and differences in cell wall thickenings of sporangia were observed among species of Albugo and different genera (e.g., Albugo, Wilsoniana and Pustula), but the developmental process of sporangial walls was not clearly revealed prior to the present study. Whether both layers, or only the inner layer of the sporogenous hypha wall are involved in the formation of the sporangial wall has been widely investigated (Khan, 1977; Soylu et al., 2003), but not resolved. In this study, ultrastructural observations clearly demonstrate that the sporangia form holoblastically, but the origin of sporangial wall is different. The both layers of the sporogenous hypha take part in the formation of the initially sporangial wall (Fig. 5A), but were not involved in the formation of the inner and outer walls in the septum of a sporangium. These observations for the developmental processes of sporogenous hyphae and formation of sporangial wall provide a better understanding of mode of sporangiogenesis.

The developmental process of sporangia in chains and septum formation was also observed here. In the formation of sporangia, an initial sporangium buds at the tip of the sporogenous hypha from a fixed locus, and is delimited by a basal septum that is converted into a sporangium (Khan, 1977). A basipetal chain of sporangia is formed by repeating this process (Fig. 5A). However, observations made in this study revealed that the development of sporangial walls within a septum occurred later than that of their lateral walls. The degradation of constricted outer walls around a septum occurred with the development of septum formation. Then, sporangial inner walls, and subsequent outer walls developed in the upper layers of a septum (Fig. 5B-D). Finally, the middle layer of the septum formed a connective structure. With continuous centripetal dissolution of the middle layer, the connective structure became progressively thinner, and eventually completely broke, allowing the sporangia to secede, as described by Khan (1977). During sporangial maturation, all sporangia developed a two-layered cell wall and cell wall thickenings showed very few changes (Fig. 6); this was attributed to characteristics of A. candida (Heller \& Thines, 2009). Therefore, to the best of our knowledge, this study for the first time provides new insights for understanding the model of sporogenous hypha development and sporangial formation in chains of $A$. candida. In the future, cryo-fixation of tissues should be employed to possibly improve the observation of cell membrane details over that of chemical fixation methods used in this study. Moreover, A. candida is a biotrophic oomycete that parasitizes various species of Brassicaceae, causing a white blister rust with remarkable convergence in behavior to unrelated rusts of basidiomycete fungi (Links et al., 2011). Isolates of $A$. candida from different plant genera or species (Pidskalny \& Rimmer, 1985), even cultivars (Soylu et al., 2003), show host specificity. Therefore, further studies on the ultrastructural differences between susceptible and resistant hosts may provide information on the virulence of $A$. candida among $B$. juncea var. tumida cultivars for crop management. Finally, with the increasing availability of oomycota genome sequence data, comparative genomic analysis may reveal the evolutionary relationship between the model of $A$. candida sporogenous hypha development and its adaptation to diverse hosts.

Funding This work was supported by the Shanghai Agriculture Applied Technology Development Program [grant number X2021-02-08-00-12-F00760], the Key Science and Technology Project of Zhejiang Province [grant number 2015C02023] and the Natural Science Foundation of China [grant number 31571950].

\section{Declarations}

Human and animal rights No human and/or animal participants were present in this research.

Informed consent All authors of this study consent to this submission.

Conflict of interest The authors declare no conflict of interest. 
Open Access This article is licensed under a Creative Commons Attribution 4.0 International License, which permits use, sharing, adaptation, distribution and reproduction in any medium or format, as long as you give appropriate credit to the original author(s) and the source, provide a link to the Creative Commons licence, and indicate if changes were made. The images or other third party material in this article are included in the article's Creative Commons licence, unless indicated otherwise in a credit line to the material. If material is not included in the article's Creative Commons licence and your intended use is not permitted by statutory regulation or exceeds the permitted use, you will need to obtain permission directly from the copyright holder. To view a copy of this licence, visit http://creativecommons.org/licenses/by/4.0/.

\section{References}

Arora H., Padmaja K.L., Paritosh K., Mukhi N., Tewari A.K., Mukhopadhyay A., Gupta V., Pradhan A.K., \& Pental D. (2019). BjuWRR1, a CC-NB-LRR gene identified in Brassica juncea, confers resistance to white rust caused by Albugo candida. Theoretical and Applied Genetics. 2019;132(8):2223-2236. https://doi.org/10. 1007/s00122-019-03350-z.

Baka, Z. A. M. (2008). Occurrence and ultrastructure of Albugo candida on a new host Arabis Alpina in Saudi Arabia. Micron, 39(8), 1138-1144. https://doi.org/10. 1016/j.micron.2008.06.001

Berlin, D., \& Bowen, C. C. (1964). The host-parasite interface of Albugo candida on Raphanus sativus. American Journal of Botany, 50(8), 445-452. https://doi.org/10. 1002/j.1537-2197.1963.tb10647.x

Bhayana, L., Paritosh, K., Heena, Arora, H., Yadava, S. K., Singh, P., Nandan, D., Mukhopadhyay, A., Gupta, V., Pradhan, A. V., \& Pental, D. (2019). A mapped locus on $\lg$ a6 of Brassica juncea line tumida conferring resistance to white rust contains a cnl type r gene. Frontiers in Plant Science, 10, 1690-1690. https://doi.org/10. 3389/fpls.2019.01690.eCollection2019

Borhan, H. M., Brose, E., Beynon, J. L., \& Holub, E. B. (2001). White rust (Albugo candida) resistance loci on three Arabidopsis chromosomes are closely linked to downy mildew (Peronospora parasitica) resistance loci. Molecular Plant Pathology, 2(2), 87-95. https://doi.org/ 10.1046/j.1364-3703.2001.00056.x

Choi, Y. J., Hong, S. B., \& Shin, H. D. (2006). Genetic diversity within the Albugo candida complex (Peronosporales, Oomycota) inferred from phylogenetic analysis of ITS rDNA and COX2 mtDNA sequences. Molecular Phylogenetics and Evolution, 40(2), 400-9. https://doi. org/10.1016/j.ympev.2006.03.023

Choi, Y. J., Shin, H. D., Hong, S. B., \& Thines, M. (2007). Morphological and molecular discrimination among Albugo candida materials infecting Capsella bursapastoris world-wide. Fungal Diversity, 27(1), 11-34. https://doi.org/10.1002/yea.1553

Choi, Y. J., Shin, H. D., Ploch, S., \& Thines, M. (2008). Evidence for uncharted biodiversity in the Albugo candida complex, with the description of a new species.
Mycological Research, 112(11), 1327-1334. https://doi. org/10.1016/j.mycres.2008.04.015

Coffey, M. D. (1975). Ultrastructural features of the haustorial apparatus of the white blister fungus Albugo candida. Canadian Journal of Botany, 53(53), 1285-1299. https://doi.org/10.1139/b75-155

Coffey, M. D. (1983). Cytochemical specialization at the haustorial interface of a biotrophic fungal parasite Albugo candida. Canadian Journal of Botany, 61(1), 2004-2014. https://doi.org/10.1139/b83-216

Constantinescu, O., \& Thines, M. (2006). Dimorphism of sporangia in Albuginaceae (chromista, peronosporomycetes). Sydowia, 58(2), 178-190.

Davison, E. M. (1968). Cytochemistry and ultrastructure of hyphae and haustoria of Peronospora parasitica (Pers. ex Fr.) Fr. Annals of Botany, 3, 613-621. https://doi.org/ 10.1016/0033-7560(67)90023-3

Heller, A., \& Thines, M. (2009). Evidence for the importance of enzymatic digestion of epidermal walls during subepidermal sporulation and pustule opening in white blister rusts (Albuginaceae). Mycological Research, 113(6-7), 657-667. https://doi.org/10.1016/j.mycres.2009.01.009

Holub, E. B., Brose, E., Tor, M., Clay, C., Crute, I. R., \& Beynon, J. L. (1995). Phenotypic and genotypic variation in the interaction between Arabidopsis thaliana and Albugo candida. Molecular Plant-Microbe Interactions, 8(6), 916-928. https://doi.org/10.1094/MPMI-8-0916

Hughes, S. J. (1971). Percurrent proliferations in fungi, algae, and mosses. Canadian Journal of Botany, 49(2), 215-231. https://doi.org/10.1139/b71-037

Kaur, P., Jost, R., Sivasithamparam, K., \& Barbetti, M. J. (2011a). Proteome analysis of the Albugo candidaBrassica juncea pathosystem reveals that the timing of the expression of defence-related genes is a crucial determinant of pathogenesis. Journal of Experimental Botany, 62(3), 1285-1298. https://doi.org/10.1093/jxb/ erq365

Kaur, P., Sivasithamparam, K., \& Barbetti, M. J. (2011b). Host range and phylogenetic relationships of Albugo candida from cruciferous hosts in Western Australia, with special reference to Brassica juncea. Plant Disease, 95(6), 712718. https://doi.org/10.1094/PDIS-10-10-0765

Khan, S. R. (1976). Ultrastructural changes in maturing sporangia of Albugo candida. Annals of Botany, 6, 12851292. https://doi.org/10.1007/BF00388861

Khan, S. R. (1977). Light and electron microscopic observations of sporangium formation in Albugo candida (peronosporales; oomycetes). Canadian Journal of Botany, 55(6), 730-739. https://doi.org/10.1139/b77-087

Links, M. G., Holub, E., Jiang, R. H. Y., Sharpe, A. G., \& Borhan, M. H. (2011). De novo sequence assembly of albugo candida reveals a small genome relative to other biotrophic oomycetes. BMC Genomics, 12(1), 503-503. https://doi.org/10.1186/1471-2164-12-503

Petkowski, J. E., Minchinton, E., Thomson, F., Faggian, R., \& Cahill, D. (2010). Races of Albugo candida causing white blister rust on brassica vegetables in Australia. Acta Horticulturae, 867(867), 133-142. https://doi.org/10.17660/ ActaHortic.2010.867.17

Pidskalny, R. S. , \& Rimmer, S. R. . (1985). Virulence of Albugo candida from turnip rape (Brassica campestris) 
and mustard (Brassica juncea) on various crucifers. Canadian Journal of Plant Pathology, 7(3), 283-286. https:// doi.org/10.1080/07060668509501692

Ploch, S., Choi, Y. J., Rost, C., Shin, H. D., Schilling, E., \& Thines, M. (2010). Evolution of diversity in Albugo is driven by high host specificity and multiple speciation events on closely related brassicaceae. Molecular Phylogenetics \& Evolution, 57(2), 812-820. https://doi.org/10. 1016/j.ympev.2010.06.026

Pound, G. S., \& Williams, P. H. (1963). Biological races of Albugo candida. Phytopathology, 53, 1146-1149.

Sokhi, S. S., \& Khangura, R. K. (1992). White rust of rapeseed and mustard (pp. 92-23). DR/Publ.

Soylu, S. (2004). Ultrastructural characterization of the hostpathogen interface in white blister-infected Arabidopsis leaves. Mycopathologia, 158(4), 457-464. https://doi.org/ 10.1007/s11046-004-2453-9

Soylu, S., Keshavarzi, M., Brown, I., \& Mansfield, J. W. (2003). Ultrastructural characterisation of interactions between Arabidopsis thaliana and Albugo candida. Physiological and Molecular Plant Pathology, 63(4), 201-211. https://doi.org/10.1016/j.pmpp.2003.12.002

Sun, Q., Zhou, G., Cai, Y., Fan, Y., \& Yang, J. (2013). Transcriptome analysis of stem development in the tumourous stem mustard Brassica juncea var. tumida Tsen et lee by RNA sequencing. BMC Plant Biology, 13(1), 90-90. https://doi.org/10.1186/1471-2229-13-90

Tewari, J. P., \& Skoropad, W. P. (1977). Ultrastructure of oospore development in Albugo candida on rapeseed.
Canadian Journal of Botany, 55(17), 2348-2357. https:// doi.org/10.1139/b77-268

Tewari, J. P., Skoropad, W. P., \& Malhotra, S. K. (1980). Multilamellar surface layer of the cell wall of Albugo candida and Phycomyces blakesleeanus. Journal of Bacteriology, 142(2), 689-693. https://doi.org/10.1128/JB.142.2.689693.1980

Thakur, S. B. (1977). Percurrent proliferation of sporangiophores in the genus Albugo. Mycologia, 69(3), 637-641. https://doi.org/10.2307/3758569

Verma, P. R., \& Petrie, G. A. (1980). Effect of seed infestation and flower bud inoculation on systemic infection of turnip rape by Albugo candida. Canadian Journal of Plant Science, 60(1), 267-271. https://doi.org/10.4141/cjps80-038

Verma, P. R., Saharan, G. S., Bartaria, A. M., \& Asha, S. (1999). Biological races of Albugo candida on Brassica juncea and Brassica rapa var. toria in India. Journal of Plant Pathology, 29, 75-82.

Voglmayr, H., \& Riethmuller, A. (2006). Phylogenetic relationships of Albugo species (white blister rusts) based on LSU rDNA sequence and oospore data. Mycological Research, 110(1), 75-85. https://doi.org/10.1016/j.mycres.2005.09. 013

Woods, A. M., \& Gay, J. L. (1983). Evidence for a neckband delimiting structural and physiological regions of the host plasma membrane associated with haustoria of Albugo candida. Physiological Plant Pathology, 23, 73-88. https://doi.org/10.1016/0048-4059(83)90035-8 